\title{
FORMAÇÃO DO ENFERMEIRO PARA ATUAR NA CENTRAL DE ESTERILIZAÇÃO
}

\author{
Training of nurses to work in the central sterile supply department nurse \\ Formación del enfermero para actuar en la central de esterilización
}

\section{Selma Maria Ravazzi Lucon', Luzmarina Aparecida Doretto Braccialli², Sueli Moreira Pirolo ${ }^{3}$, Cláudia Cordeiro Munhoz ${ }^{4}$}

RESUMO: Objetivo: Compreender a formação do enfermeiro para atuar na Central de Material Esterilizado (CME). Método: Estudo descritivo qualitativo, constituído por uma amostra de 20 enfermeiros matriculados nos programas de mestrado profissional e acadêmico da Faculdade de Medicina de Marília (Famema), no período de 2011 a 2014. A coleta de dados foi realizada por meio de entrevista em 2014. Resultados: Foram identificadas duas categorias temáticas: a formação do enfermeiro pautada no modelo tecnicista e a perspectiva da formação generalista. Constatou-se que o mundo do trabalho e a formação estão entrelaçados, sendo que a graduação contribui para o desenvolvimento de profissionais competentes e éticos, considerando as suas realidades nos processos de formação. Conclusão: Independente da proposta curricular das instituições de ensino, os enfermeiros tiveram dificuldades para o aprofundamento quanto ao tema proposto, mas colaboraram com sugestões de transformações das práticas de ensino e aprendizagem para atuação dos enfermeiros na CME e que essa formação possa ser repensada mais adequadamente.

Palavras-chave: Educação em enfermagem. Administração de materiais no hospital. Esterilização.

ABSTRACT: Objective: To understand the training of nurses who will work in the Central Sterile Supply Department (CSSD). Method: Descriptive and qualitative study including a sample of 20 nurses enrolled in the professional and academic Master's Degree Programs of Faculdade de Medicina de Marilia (Famema), in the period 2011 to 2014. The data were collected by interviews in 2014. Results: We found two thematic categories: nurse training based on the technicist model and the perspective of generalist training. The world of work and training are intertwined and the undergraduation course, therefore, contributes to the development of competent and ethical professionals, since it considers their realities in training processes. Conclusion: Regardless of teaching institutions' curriculum, nurses faced difficulties in studying the proposed theme further; however, they have collaborated with suggestions regarding changes in the teaching and learning practices for nurses that work in the CSSD; and they have also suggested it could be reconsidered in a better way.

Keywords: Education, nursing. Materials management, hospital. Sterilization.

RESUMEN: Objetivo: Comprender la formación del enfermero para actuar en la Central de Material Esterilizado (CME). Método: Estudio descriptivo cualitativo, constituido por una muestra de 20 enfermeros matriculados en los programas de maestrando profesional y académico de la Facultad de Medicina de Marília (Famema), en el período de 2011 a 2014. La colecta de datos fue realizada por medio de entrevista en 2014. Resultados: Fueron identificadas dos categorías temáticas: la formación del enfermero pautada en el modelo tecnicista y la perspectiva de la formación generalista. Se constató que el mundo del trabajo y la formación están entrelazados, siendo que la graduación contribuye para el desarrollo de profesionales competentes y éticos, considerando sus realidades en los procesos de formación. Conclusión: Independiente de la propuesta curricular de las instituciones de enseñanza, los enfermeros tuvieron dificultades para la profundización cuanto al tema propuesto, pero colaboraron con sugerencias de transformaciones de las prácticas de enseñanza y aprendizaje para actuación de los enfermeros en la CME y que esa formación pueda ser repensada más adecuadamente.

Palavras clave: Educación en enfermería. Administración de materiales de hospital. Esterilización.

'Enfermeira e Mestre em Ensino em Saúde pela Faculdade de Medicina de Marília (Famema) - Marília (SP), Brasil. E-mail: selmamrl@famema.br Rua Doutor João Valverde, 16 - Fragata - CEP: 17.519-160 - Marília (SP), Brasil.

¿Enfermeira, docente da Famema, doutora em Ciências pela Escola de Enfermagem da Universidade de São Paulo (USP) - São Paulo (SP), Brasil.

${ }^{3}$ Enfermeira, docente da Famema, doutora em Enfermagem pela Escola de Enfermagem da USP - São Paulo (SP), Brasil.

«Enfermeira, especialista em Formação Didática Pedagógica em Enfermagem. Responsável pela Central de Material Esterilizado da Irmandade da Santa Casa de Misericórdia de Marília - Marília (SP), Brasil. Recebido: 29 nov. 2016 - Aprovado: 31 jan. 2017

DOI: 10.5327/Z1414-4425201700020006 


\section{INTRODUÇÃO}

A Central de Material Esterilizado (CME) é uma unidade fundamental do hospital, integra sua infraestrutura e colabora para o atendimento dos usuários por meio de uma atuação constituída por etapas de produção interna, serviço da área de saúde considerado importante e que pode ser classificado como cuidado ${ }^{1}$. Posto isso, formadores e estudantes devem atentar-se à importância da CME

A atuação dos enfermeiros na $\mathrm{CME}$ requer conhecimentos específicos sobre a diversidade de equipamentos, artigos e instrumental cirúrgico, assim como a forma de processá -los. Configura-se como uma área do saber da Enfermagem, cujo propósito é garantir produtos seguros para a assistência ao paciente ${ }^{1}$.

O Conselho Federal de Enfermagem (COFEN) normatiza a obrigatoriedade de enfermeiros em todas as unidades dos serviços que desenvolvem ações de enfermagem de alta complexidade, comuns na assistência a pacientes críticos².

Nos últimos anos, a formação em saúde, em especial a de enfermeiros, passou por inúmeras transformações. Na área da CME, aparentemente tem havido um distanciamento entre a formação e a prática profissional. Várias mudanças que envolvem os procedimentos ocorreram, a saber: na legislação, nas recomendações necessárias à segurança e à qualidade do processamento de artigos médico-hospitalares e nos aspectos de biossegurança. Mesmo que rotineiros, esses procedimentos podem gerar inúmeras consequências em razão do despreparo profissional.

No que diz respeito à formação dos profissionais de saúde, o Ministério da Educação propôs as Diretrizes Curriculares Nacionais (DCNs) para os cursos da área da saúde, visando à transformação das práticas de ensino, uma vez que esse processo era conduzido de forma apartada da realidade vivenciada nos serviços dessa área.

Conforme é compreendido na área da educação em Enfermagem, existem propostas de transformações das quais se contemplam aspectos pedagógicos e filosóficos, respaldados pela Resolução do Conselho Nacional de Educação que institui as DCNs no Brasil. Essas diretrizes objetivam a formação profissional, preparando os estudantes para os desafios das mudanças da sociedade, no mundo e na própria atuação, que contemplem as necessidades sociais, o sistema de saúde brasileiro e o trabalho em equipe. Ao buscar conhecimento como algo inacabado e processual, não se deve compreender a educação em Enfermagem como uma sequência de ações padronizadas, e sim como uma troca de saberes científicos e populares ${ }^{3}$.

Entretanto, o ensino tradicional predomina no desenvolvimento formativo de enfermeiros, com conhecimentos ministrados de forma fragmentada, contribuindo pouco para a formação crítica e transformadora que o novo contexto de atenção à saúde passou a exigir ${ }^{4}$.

Contudo, verifica-se uma tentativa de mudança do paradigma e do comportamento por parte de enfermeiros, que conduz à reeducação por meio dos pressupostos, agregando valores e percepções que podem vir a formar uma determinada visão da realidade, reconhecendo o potencial humano como um trunfo para a instituição, devendo tais profissionais serem respeitados como condutores e formadores de uma realidade 5 .

Diante da necessidade de formação de profissionais comprometidos com os avanços tecnológicos e científicos da área, tendo como finalidade a qualificação do aprendizado e da assistência, pergunta-se: o enfermeiro, durante a graduação, é preparado para atuar na CME?

\section{OBJETIVO}

Compreender a formação do enfermeiro para atuar na CME.

\section{MÉTODO}

Pesquisa descritiva, descrevendo situações, acontecimentos e como se manifestam determinados fenômenos ${ }^{6}$; e de abordagem qualitativa, opção feita por se tratar do universo dos motivos e significados, das aspirações e crenças, dos valores e das atitudes, favorecendo aos participantes a expressão de opiniões e sentimentos vivenciados ${ }^{7}$.

Este estudo foi desenvolvido com os enfermeiros estudantes dos programas de mestrado profissional e acadêmico da Famema, ambos multiprofissionais. A população do estudo compôs uma amostra aleatória por conveniência de 20 indivíduos, no período de 2011 a 2014, sendo que foram ofertadas 15 vagas por curso e que o total de enfermeiros foi semelhante em cada um deles.

Os participantes graduaram-se em cinco diferentes instituições de ensino superior (IES), as quais não foram identificadas quanto ao currículo adotado. Para critério de inclusão foi considerado enfermeiro matriculado nos programas de pós-graduação, como aluno regular e; de exclusão, 
a impossibilidade ou recusa de participação. Para manter o anonimato dos participantes foi utilizada a letra $\mathrm{P}$ e o número sequencial de entrevistas.

Para a coleta de dados foram realizadas entrevistas de outubro a novembro de 2014 , gravadas com o consentimento dos participantes e transcritas na íntegra.

O projeto foi encaminhado ao Comitê de Ética e Pesquisa da Famema e aprovado sob o CAAE 25424013.4.0000.5413, conforme estabelecido na Resolução n ${ }^{\circ} 466 / 12$ do Conselho Nacional de Saúde ${ }^{8}$.

A análise dos dados se deu pela técnica de análise de conteúdo de Bardin ${ }^{9}$.

No estudo, optou-se pela modalidade temática por ser uma das formas mais adequadas à investigação ${ }^{7}$. Identificou-se, assim, duas categorias: a formação do enfermeiro pautada no modelo tecnicista e a perspectiva da formação do enfermeiro generalista. Os dados de identificação dos entrevistados foram submetidos à análise descritiva.

\section{RESULTADOS}

No grupo de enfermeiros analisado, $85 \%$ dos indivíduos eram do sexo feminino e $15 \%$, do masculino. Houve variação de idade - entre 25 e 49 anos - com média de 34 anos (70\%). A amostra constituiu-se de 18 enfermeiros (80\%) atuantes, concomitantemente, na assistência e na docência, e $2(20 \%)$ que atuavam somente na gestão. Em relação à graduação, 68\% haviam se formado nos últimos 10 anos, sendo que $55 \%$ dos participantes se formaram entre os anos 1998 e 2008.

A leitura árdua e minuciosa dos depoimentos e registros possibilitou identificar as semelhanças, diferenças e contradições em consonância com as duas categorias descritas.

\section{A formação do enfermeiro pautada no modelo tecnicista}

O participante declara que, quando realizou pontualmente o estágio nessa área, sentiu-se apenas como mão de obra e teve dificuldade de apreender, identificar suas lacunas de conhecimento e aprofundar sua fundamentação teórica.

[...] a gente que era simplesmente mão de obra, ajudava a lavar material, ficava o dia inteiro enrolando gaze e seringa. (P4)
Os depoimentos apontam que a construção do aprendizado necessita da articulação entre teoria e prática:

$\mathrm{Na}$ minha formação, no modelo tradicional, a gente trabalhava muito a questão da central de materiais. A gente tinha de montar pacotes, identificar, fazer aqueles pacotes [...]. Ajudou na minha formação. É claro que a gente focava mais no fazer, era mais tarefeiro. A professora fazia a gente assumir a central como se fôssemos funcionários da casa. (P7)

Não aprofundou em nada na prática não, só foi lá para montar pacote e ir embora. A gente não pensava mais em nada. (P11)

A preocupação com o modo como o estudante vivenciará o processo de trabalho também foi mencionada na pesquisa, porém, por ainda estar em formação, esse futuro profissional precisa ser estimulado a buscar o conhecimento, pois isso interferirá diretamente na qualidade da assistência prestada aos pacientes.

Não dar teoria, mas colocar eles lá no cenário e, a partir dali, levantar os questionamentos, a vivência. Enfim, ter a fundamentação. (P7)

Também foi destacado o distanciamento entre a teoria e a prática, ou seja, o que é discutido na teoria e o que se vivencia na prática profissional.

Na graduação a gente até teve uma pequena aproximação em relação a esses processos de limpeza, desinfecção, esterilização. Só na parte teórica, não tivemos a parte prática. A gente demanda muito a questão da prática para poder embasar a teoria e voltar para prática. (P3)

O sentimento de inferioridade da área é verbalizado, apesar de ser considerado um espaço de construção de extrema relevância para o cuidado.

Dizemos até que a Central de Material é o coração do hospital, embora digam que todos que não "prestam" têm de atuar em uma Central. Vemos que é o inverso, este é o lugar onde 
deveria ter pessoas melhor instruídas, capacitadas, comprometidas, porque uma falha ali vai gerar um problema na saúde de todo o hospital. (P15)

Os enfermeiros que irão atuar na CME precisam estar aptos a ensinar os demais colegas e demonstrar confiança ao realizar as atividades, além de valorizar o serviço.

Acho que os enfermeiros assistenciais precisam dar mais importância e também precisam transmitir isso aos alunos, porque ficaria melhor e o serviço seria mais valorizado. $(\mathrm{P} 9)$

Em alguns currículos de formação para enfermeiros, o conteúdo específico de CME foi abordado em uma disciplina, mas mesmo assim o entrevistado considera que a formação para sua atuação foi insuficiente e que esse assunto deveria ser abordado de forma mais abrangente durante toda a graduação.

A gente não vê isso nas disciplinas da nossa faculdade. Até se comenta alguma coisa talvez dentro da disciplina de centro cirúrgico, mas é muito vago, muito curto, não é uma formação específica. Como sugestão, acho que deveria ter uma formação mais abrangente sobre o assunto, acho que isso ainda está muito perdido. (P19)

\section{A perspectiva da formação do enfermeiro generalista}

Seria importante para esse participante que o profissional enfermeiro tivesse tido uma visão generalista durante o processo de formação, pois durante sua vida profissional essa prática poderia ser mais bem desenvolvida, proporcionando conhecimento em todas as especialidades.

Vejo que é importante [abordar] especificidades durante a formação, até para dar oportunidade para o enfermeiro escolher. (P6)

Os momentos de discussões e as vivências do funcionamento da CME durante a graduação de Enfermagem fortalecem a formação do generalista crítico e reflexivo para também atender à demanda do mercado.
Vimos as RDC [resolução da diretoria colegiada] de como deve ser o lugar, como deve ser organizada a entrada e a saída de material por portas diferentes, a estrutura e deu até para fazer uma análise crítica do que a gente tinha no hospital, se isso era adequado ou não. (P9)

Para o desenvolvimento do aprendizado durante a graduação, foi de suma importância a melhor identificação do papel do enfermeiro da CME, assim como a sua presença nesse estabelecimento.

Eu acho que teria que ter uma aproximação maior com o cenário de prática, com a intenção da mudança, de mostrar qual é a função do enfermeiro dentro de uma central, da avaliação de todo o complexo que tem ali dentro e é muito específico. É preciso ver como que é a ação do enfermeiro lá dentro, de prevenção, educação, atuação em cima daquilo tudo, da equipe. (P11)

Acho que CME devia fazer parte de uma vivência prática. Estamos envolvidos diretamente com os fluidos corporais e temos de ter o mínimo de compreensão, de educação sobre isso. Na graduação não foi tão forte, apesar de ter uma metodologia de problematização. (P16)

A especialização e o contato na graduação podem aprofundar o conhecimento nessa área, auxiliando na formação do enfermeiro, principalmente para atuação em qualquer contexto de atenção à saúde, além de que, o estudante, tendo o apoio do docente, relembra todo o seu aprendizado.

Eu acho que tinha que voltar a ter o estágio na central de material e centro cirúrgico, porque a gente não consegue mais, ficou uma área para especialização. Eu acho que deveria sim estar inserido nos currículos, eu tive a oportunidade de ver isso na minha graduação. (P17)

É importante, não tem dúvida, porque quem lida com toda a parte de material é a Enfermagem. Só que penso que não deve ser uma coisa só da central de material. Eu acho que a área de processamento tem de ser abordada o tempo todo, não é uma coisa estanque. Eu sugeriria que tivesse essa abordagem durante todos os conteúdos. (P18) 


\section{DISCUSSÃO}

A formação do enfermeiro tecnicista, traduzida nos depoimentos por meio de procedimentos e tarefas, (des)articulação entre teoria e prática, (des)valorização e procura por especialidades, considera o conhecimento referente à CME de grande importância para a condução de suas atividades atuais, de forma a garantir a segurança e a qualidade dos artigos a serem utilizados pelos profissionais.

Esses profissionais sinalizam a necessidade de capacitação para quem acompanha essa área do conhecimento, como forma de garantir a qualidade do serviço prestado e manter níveis reduzidos de riscos de agravo à saúde dos usuários, em relação à complexidade dos processos de esterilização, ao alto custo para a aquisição de instrumentos cirúrgicos e equipamentos mais sofisticados, além dos investimentos na qualificação do profissional da CME.

Para que o enfermeiro possa desempenhar suas atividades pautadas nos conceitos recentes dentro da obrigatoriedade exigida por legislações, o modelo tecnicista pode representar um desafio para as correntes emergentes dos cuidados ampliados, principalmente porque o enfermeiro atuante de CME vai além do saber realizar procedimentos adequados. Ele necessita de conhecimentos básicos para apresentar qualidade e segurança dos artigos que dispõe a seus usuários, além de coordenar eficientemente a sua equipe.

Dessa forma, é fundamental que haja a integralidade no foco nas ações em saúde aos usuários, não usando somente a fragmentação dos cuidados, mas objetivando a lógica de horizontalização dos saberes ${ }^{10}$.

Nessa perspectiva, as DCNs estabelecem que os graduandos se tornem profissionais competentes e com habilidades para que possam apresentar o perfil desejado, ou seja, o de profissionais generalistas, críticos, reflexivos, além de possuírem as competências técnico-científica, ético-política e socioeducativa, para que se tornem seguros nas ações do cuidado que irão desempenhar. A questão da formação para a saúde pautada nos princípios do Sistema Único de Saúde (SUS) pode ser considerada atualmente uma das demandas para a formação profissional, tornando necessária a capacidade para enfrentar os desafios apontados nos serviços, com a devida compreensão e consciência crítica da realidade na qual estão inseridos, incluindo as transformações das práticas assistenciais voltadas para a integralidade e justiça social ${ }^{11}$.

Observou-se no estudo que nem todos os profissionais compreendem a finalidade da CME; eles verbalizam o seu descontentamento, manifestando desconhecimento e desvalorização dos profissionais que trabalham nesse local. Os próprios profissionais manifestaram sentimentos de depreciação das atividades. Eles almejam ser reconhecidos e valorizados e, para isso, buscam continuamente superar as dificuldades.

Grande parte dos hospitais e das unidades de saúde que possui CME insere enfermeiros para a condução dos seus trabalhos. Portanto, em relação ao gerenciamento, o cargo na CME precisa ser ocupado por um profissional de saúde de nível superior com qualificação específica, experiência na área e que responda legalmente às ações ali realizadas. Percebe-se, assim, que o profissional de Enfermagem tem perfil apropriado para realizá-lo ${ }^{12}$.

Emum parecer técnico do Conselho Regional de Enfermagem (Coren) de 2012, houve um questionamento sobre as atribuições legais que podem ser desenvolvidas pela equipe de enfermagem na CME e sobre a responsabilidade do enfermeiro. Tais funções estão descritas na Resolução da Diretoria Colegiada da Agência Nacional de Vigilância Sanitária (RDC/ANVISA), de 15 de março de 2012, e na Lei do Exercício Profissional de Enfermagem n ${ }^{\circ}$ 7.498/1986, em relação à equipe e à enfermeira. Na graduação, o enfermeiro deve ser preparado para tais atividades, além de historicamente assumir todo o processo de gerenciamento da CME nos serviços de saúde ${ }^{13}$.

Outro estudo sinaliza a valorização dos profissionais que atuam em CME. Aponta-se que os administradores dos hospitais precisam se conscientizar melhor sobre as necessidades da CME e necessitam dar mais atenção a seus profissionais; apesar de sua atuação indireta com o paciente, ela é tão importante quanto aquelas de execução direta ${ }^{14}$.

Para a formação do enfermeiro generalista, é fundamental que ele, profissional, durante a sua formação, conheça a CME. Embora não envolva diretamente os pacientes, essa unidade hospitalar é um campo de aprendizado e de atuação profissional.

Como a complexidade envolve as atividades de processamento, isso implica que os enfermeiros busquem processos educativos formais que abranjam todas as ações desenvolvidas sistematicamente em curto, médio ou longo prazo, objetivando aumentar a própria capacitação profissional. Disso resulta a ampliação das habilidades profissionais relativas à eficiência na realização das atividades desenvolvidas ${ }^{15}$.

Visando mudar o paradigma na formação dos enfermeiros, buscam-se novas metodologias de ensino e currículos alternativos que respondam aos problemas de saúde da população. Para superar tal lógica, propõem-se práticas educativas que valorizem a preparação e a motivação dos estudantes, 
formando profissionais críticos, motivados, criativos, flexíveis e comprometidos com o objetivo de sua atuação.

Muitas instituições de ensino na saúde já adotam métodos ativos de aprendizagem, proporcionando aos estudantes a independência e a responsabilidade pelo seu próprio estudo. São apoiados pela aprendizagem por descoberta e significativa, valorizam o aprender a aprender, estimulam a gestão participativa dos protagonistas da experiência e a reorganização da relação teoria/prática. Nesse contexto, os alunos passam a se reconhecer como responsáveis pelo seu próprio aprendizado e desfrutam da autonomia na (re)construção do conhecimento. Tornam-se aptos a interligar saberes e experiências prévias àquelas disponibilizadas no meio científico. Conseguem, ainda, desenvolver habilidades para religar saberes, antes fragmentados e desconexos, para a autonomia na busca de conhecimento pertinente, incitando a atualização contínua e despertando o senso crítico sobre os materiais científicos com os quais passam a ter mais contato ${ }^{16}$.

Como o trabalho na CME se reflete diretamente na qualidade da assistência prestada ao cliente, seu bom funcionamento requer o trabalho conjunto de pessoal capacitado técnica e cientificamente e em número adequado para exercer um conjunto de tarefas de grande especificidade ${ }^{14}$.

Essas competências expressam ideias importantes para que se analise a formação do enfermeiro, pois trazem avanços para a prática profissional ao propor o desenvolvimento de capacidades para que ele se torne proativo e integrado ao contexto social e supere o foco da especialidade. As DCNs, com seus 16 anos de funcionamento, nos possibilitam apreender $\mathrm{o}$ quanto os egressos têm traduzido essas diretrizes na prática.

Há necessidade de profissionais que consigam acompanhar todas as evoluções existentes no mercado de trabalho, visando garantir a qualidade do serviço prestado e também manter níveis reduzidos dos riscos de agravo à saúde dos usuários. O estudo revelou que muitos dos enfermeiros ainda necessitam de maior conhecimento nessa área, questão relatada por eles diante da pouca inserção durante o processo de formação. Por esse motivo, é necessário entender que os enfermeiros devem sair de sua graduação com os conhecimentos básicos sobre CME.

Alguns depoimentos mencionaram a falta de compreensão sobre o processo de trabalho realizado na CME, resultado do pouco envolvimento com a formação.

Praticamente todos os entrevistados expressaram valorização do trabalho realizado nesse setor e destacaram sua importância. Embora tenham sido relatadas algumas experiências em relação aos processamentos de materiais, o que predominou no estudo foi o desconhecimento total ou parcial das atividades que são realizadas nesses locais, salientando-se o mecanicismo que permeou grande parte dos depoimentos.

A prestação de cuidados qualificada aos usuários das unidades de saúde requer que os trabalhadores da CME, em especial os enfermeiros, a quem cabe a gestão do processo de trabalho, sejam muito bem capacitados para responder às demandas das demais áreas hospitalares, inclusive as mais críticas.

Quanto aos conteúdos abordados durante a graduação, os profissionais apontam deficiências nos métodos de ensino, sentem falta de conteúdos e maior apropriação de conhecimentos, principalmente nos cenários de prática da CME. Isso tem ocorrido tanto em IES que adotam metodologias tradicionais quanto naquelas que optam por metodologias ativas. Os cenários de prática parecem ser o ponto-chave para que os futuros enfermeiros possam adquirir maior conhecimento. Os entrevistados consideram necessário aproximar o ensino da realidade dos serviços de saúde, pois o campo da prática não pode ser tratado como algo à parte do desenvolvimento curricular.

As transformações nos currículos da enfermagem vêm ocorrendo paulatinamente, apesar de ainda existir, em sua maioria, a predominância do modelo médico-hospitalar para o curso de graduação.

A literatura mostra que existe um movimento de mudança na formação do enfermeiro brasileiro; mas, para vencer os desafios e implementar o novo no processo de formação, é necessário diminuir as resistências às mudanças e propor reflexões sobre a docência. Constata-se a assistência de matrizes curriculares que ainda estão estruturadas por disciplinas; a existência de referencial pedagógico problematizador, que surge em contraposição a dificuldades de inserção no cenário real; e também a predominância do valor teórico sobre a prática, buscando estratégias que levem à diminuição do distanciamento dos serviços de saúde, com o reforço à clássica dicotomia entre o pensar e o fazer. Além disso, é possível observar, principalmente em IES de cunho privado, um número excessivo de alunos e o surgimento de dificuldades com o estabelecimento de parcerias com os serviços de saúde, sem contar a contratação de docentes, que é incompatível com as reais necessidades ${ }^{17}$.

O fato dos processos formativos da enfermagem abordarem o tema superficialmente, como evidenciaram os depoimentos, pode provocar, nos estudantes, certo distanciamento, 
e o receio do desconhecido pode levá-los a não se aprofundarem na área. Enfermeiros recém-formados, por vezes, precisaram procurar cursos de pós-graduação para se especializar e, assim, diminuir sua lacuna de conhecimento ao trabalhar em um setor relativamente desconhecido.

\section{CONCLUSÃO}

A metodologia adotada possibilitou atender ao objetivo proposto de compreender a formação do enfermeiro, a qual permitiu identificar a necessidade de maior envolvimento entre a teoria e a prática para otimizar seu exercício profissional em conjunto com os conteúdos abordados e aplicados durante a formação.

Observou-se também que os modelos de formação perpassam a busca de modelos inovadores no decorrer dos anos, para melhorar os processos de ensino-aprendizagem; porém, condições ideais ainda são necessárias para alcançar tal objetivo.

Destaca-se, como ponto positivo, que a CME, como uma área do cuidado, apresenta sua importância para as unidades de saúde em relação aos processos que são realizados. Além disso, constata-se que o enfermeiro deveria sair da graduação com conhecimentos básicos sobre essa área. O que chama a atenção, porém, é que esses profissionais, durante seu período de graduação, não tiveram muito interesse em se aprofundar nesse tema. Não houve estímulo em buscar esse conhecimento, alguns por vontade própria, outros por não terem tido o contato necessário, ou porque não se identificaram pela área. Deixemos essa questão para uma investigação futura em conjunto com as IES. É necessário que se analise o que está dificultando o estímulo dos graduandos ou o que falta para despertar o interesse por áreas específicas como a CME.

Entre as fragilidades conhecidas, registra-se a formação tradicional, que ainda ocorre de forma fragmentada, sendo apontada a existência de um enfoque hospitalocêntrico, o que pode prejudicar o desenvolvimento das suas competências.

Durante o decorrer do estudo ocorreram algumas limitações, como o aporte teórico insuficiente e a produção de muitos anos. Ainda assim, foi realizada a interação com os depoimentos e os ajustes possíveis durante a inclusão das limitações.

Isso também pode significar aspectos de relevância deste estudo, ou seja, a lacuna que existe em relação ao tema e a importância de se tornar público algo que não esteja em evidência.

Espera-se que este estudo contribua para dar visibilidade à formação profissional para a CME como uma área relevante na saúde, e que proporcione novos olhares em relação às metodologias de ensino, com o intuito de melhorar as condutas e as percepções da Enfermagem sobre esse campo de atuação profissional.

\section{REFERÊNCIAS}

1. Possari JF. Centro de material e esterilização: planejamento, organização e gestão. $4^{\mathrm{a}}$ ed. São Paulo: látria; 2012.

2. Brasil. Decreto n. 94.406 , de 8 de junho de 1987. Regulamenta a Lei n. 7.498, de 25 de junho de 1986, que dispõe sobre o exercício da Enfermagem, e dá outras providências. Diário Oficial da União. 9 jun. 1987; Seção I:8.853.

3. Brasil. Ministério da Educação, Conselho Nacional de Educação, Câmara de Educação Superior. Resolução CNE/CES n. 3, de 7 de novembro de 2001. Institui diretrizes curriculares nacionais do curso de graduação em Enfermagem. Diário Oficial da União. 9 nov. 2001;Seção 1:37.

4. Quadros JS, Colomé JS. Metodologias de ensino-aprendizagem na formação do enfermeiro. Rev Baiana Enferm [Internet]. 2016 [citado 2016 out.25];30(2):1-10. Disponível em: http://dx.doi.org/10.18471/ rbe.v30i2.15662
5. Pezzi MCS. Reconstruindo formas de gerenciar recursos humanos: a prática do enfermeiro na central de material e esterilização [dissertação]. Rio de Janeiro (RJ): Universidade Federal do Rio de Janeiro; 2011 [citado 2016 jun. 10]. 234p. Disponível em: http://objdig. ufrj.br/51/teses/EEAN_D_MariaDaConceicaoSamuPezzi.pdf

6. Hernandez Sampieri R, Fernandez Collado C, Baptista Lucio M. Metodologia de pesquisa. 5a ed. Porto Alegre: Penso; 2013.

7. Minayo MCS. 0 desafio do conhecimento: pesquisa qualitativa em saúde. 13a ed. São Paulo: Hucitec; 2013.

8. Brasil. Ministério da Saúde. Conselho Nacional de Saúde. Resolução n. ${ }^{\circ}$ 466, de 12 de dezembro de 2012. Aprova as diretrizes e normas regulamentadoras de pesquisas envolvendo seres humanos. Diário Oficial da União. 13 jun. 2013; Seção 1:59.

9. Bardin L. Análise de conteúdo. São Paulo: Edições 70; 2012. 
10. Saldanha OMFL, Pereira ALB, Medeiros CRG, Dhein G, Koetz LCE, Schwertner SF, et al. Clínica-escola: apoio institucional inovador às práticas de gestão e atenção na saúde como parte da integração ensino-serviço. Interface Comum Saúde Educ [Internet]. 2014 [citado 2016 abr. 20];18(Supl 1):1053-62. Disponível em: http://dx.doi. org/10.1590/1807-57622013.0446

11. Fernandes JD, Silva RMO, Teixeira GA, Florencio RMS, Silva LS, Rebouças LCC. Aderência de cursos de graduação em enfermagem às diretrizes curriculares nacionais na perspectiva do sistema único de saúde. Esc Anna Nery [Internet]. 2013 [citado 2016abr.5];17(1):829. Disponivel em: http://www.scielo.br/pdf/ean/v17n1/12.pdf

12. Brasil. Ministério da Saúde. Orientações gerais para central de esterilização. Brasília: Ministério da Saúde; 2001.

13. Conselho Regional de Enfermagem de São Paulo [Internet]. Parecer n. 3, de 5 de julho de 2012. Dispõe sobre as atribuições dos profissionais de enfermagem no Centro de Material e Esterilização - CME. São Paulo: Coren-SP; 2012 [citado 2016 jun. 28]. Disponível em: http://portal.coren-sp.gov.br/sites/default/files/parecer_coren_ sp_2012_3.pdf

14. Florêncio ACUS, Carvalho R, Barbosa GS. O impacto do trabalho do centro de materiais na qualidade da assistência. Rev SOBECC. 2011;16(1):31-9.

15. Padoveze MC, Figueiredo RM, Pelaes CES, Otrenti E. Necessidades de aprendizagem de enfermeiros sobre processos de esterilização. Rev SOBECC. 2013;18(3):23-9.

16. Campos LRG, Ribeiro MRR, Depes VBS. Autonomia do graduando em enfermagem na (re)construção do conhecimento mediado pela aprendizagem baseada em problemas. Rev Bras Enferm [Internet]. 2014 [citado 2016 abr. 5];67(5):818-24. Disponível em: http://dx.doi. org/10.1590/0034-7167.2014670521

17. Soriano ECI, Peres CRFB, Marin MJS, Tonhom SFR. State nursing courses in São Paulo forward the curriculum guidelines. Rev Min Enferm [Internet]. 2015 [citado em 2016 abr. 5];19(4):973-9. Disponível em: http://www.reme.org.br/artigo/detalhes/1053 